Open Access

\title{
Family patronage, institutional patronage, and work family conflict: women's employment status and subjective well-being in urban China
}

\author{
Yuxiao Wu $^{1 *}$ D, Peng Wang ${ }^{2}$ and Chao Huang ${ }^{1}$
}

* Correspondence:

yxwu2013@nju.edu.cn

1 Department of Sociology, Nanjing University, Nanjing, China

Full list of author information is available at the end of the article

\begin{abstract}
This paper concerns women's life chances by investigating the relationship between women's employment status and their subjective well-being. Based on the segmented labor market structure in urban China, we divide urban women into three groups, i.e., women working in the public sector, women working in the private sector, and women who are not in the labor market. Analyzing data from the 2013 Chinese General Social Survey, we find that (1) married women in better family economic situations are more likely to opt out of the labor force; (2) compared to women working in the public sector, women working in the private sector spend more hours in paid work per week; and (3) among the three groups, women working in the private sector have the lowest level of subjective well-being. Adopting the new institutionalist perspective, we propose three mechanisms, i.e., family patronage, institutional patronage, and work-family conflict, to interpret the empirical findings. Our research highlights how women's employment and subjective well-being are shaped both by institutional context and normative environment.
\end{abstract}

Keywords: Family patronage, Institutional patronage, Work-family conflict, Women's employment, Subjective well-being

\section{Introduction}

Women's employment status is one of the most important and commonly used indicators to measure their socio-economic status. It also has a strong correlation with gender inequality in the labor market and within households. Since the beginning of the market transition in 1978, China has been experiencing fast growth in the economy, expansion of tertiary industries, and an increase in educational attainment for women, all of which predict increases in women's employment. However, rates of women's labor force participation in China have been consistently dropping since the early 1980s. Data published on the official website of the World Bank shows that female employment rates in China dropped steadily from $72.7 \%$ in 1990 to $63.9 \%$ in 2013. The dominating explanation for the downward shift in women's employment contends that, since the market reform, employment is no longer a compulsory policy of the state, and this has allowed women to more easily withdraw from

(c) 2016 The Author(s). Open Access This article is distributed under the terms of the Creative Commons Attribution 4.0 International License (http://creativecommons.org/licenses/by/4.0/), which permits unrestricted use, distribution, and reproduction in any medium, provided you give appropriate credit to the original author(s) and the source, provide a link to the Creative Commons license, and indicate if changes were made. 
work (Parish and Busse 2000). Another representative view argues that the process of marketization creates incentives to discriminate based on gender as a result of the waning focus on gender equality, which occurred during the redistributive stage, and as state interventions in the labor market have decreased. As a result, women may be inclined to leave the labor market, leading to the decline in women's employment (Pan 2002). A third view of this phenomenon argues that the decline in the employment rate for women is caused directly by radical labor policies, e.g., the policy for laying off workers in state-owned enterprises that was initiated in the mid-1990s (Cai and Wang 2004).

Previous studies have mainly discussed causes that led to the decreasing trend in women's employment rate, while paying less attention to two dimensions that are important to understanding women's labor force participation in China. On the one hand, regarding women's employment status, most current studies divide women into two groups, i.e., women in the labor force and women out of the labor force, treating all employed women as a highly homogeneous group. This approach neglects the institutional complexity - the divide between state sector and non-state sector-of transitional China. It is well known that, during this market transition, the Chinese labor market has been segmented, such that the state (public) sector and the private (non-state) sector coexist. The two sectors differ greatly in their rules and hiring process, determinants of wages and pensions, welfare, and even social security and labor rights, etc.

On the other hand, most of the existing literature examines the factors that affect Chinese women's labor supply, while not paying enough attention to the consequences of employment, particularly to the impacts that employment or unemployment have on women's subjective well-being in China. According to Jahoda (1982), employment has latent functions that meet the various psychological needs of individuals. Unemployment or not participating in the labor market will prevent those needs from being filled and therefore have a negative influence on subjective well-being or mental health. Findings from empirical studies on various societies confirm that the subjective well-being or mental health levels of people who are employed is significantly higher than those who are not (Dolan et al. 2008). In China, a recent study has explained that the subjective well-being of those who are currently employed is much higher than it is for people who are not working (Bian and Xiao 2014). Easterlin and colleagues (Easterlin et al. 2012) found that changes to Chinese residents' subjective well-being during the transition period are closely related to fluctuations in the unemployment rate. Therefore, given the context of the continuous decline in the female employment rate, it is important to understand the relationship between women's employment status and women's subjective well-being.

This paper aims to provide a comprehensive analytical framework for analyzing the factors affecting female employment status in urban China and the relationship between women's employment and their subjective well-being. Based on the segmented labor market structure in urban China, we divide women into three groups, i.e., women working in the public sector, women working in the private sector, and women who are not in the labor market. These three types of employment status lead to different structural positions and opportunities in society (even within the family) for individuals. We argue that women's subjective well-being may be shaped by structural factors in the labor market and corresponding formal or informal institutional environments within 
society, although their well-being is usually considered to arise from perceptions about their own lives. Employing the theoretical perspective of new institutionalism, we propose three mechanisms, i.e., family patronage, institutional patronage, and workfamily conflict, to understand and interpret women's employment status and its relationship with subjective well-being in urban China. Specifically, we hypothesize that (1) family patronage, which is measured by marriage and family economic situation, is negatively associated with women's labor force attachment; (2) family patronage is positively associated with women's subjective well-being; (3) institutional patronage, which is measured by whether one works in the public sector, is positively associated with women's subjective well-being; and (4) work-family conflict is one of the mediating factors that connects women's employment status and subjective well-being.

\section{Literature review}

\section{Employment and subjective well-being}

According to Veenhoven (1991), subjective well-being (also termed happiness) refers to the individual's overall positive evaluation of life, including emotional and cognitive factors. Diener (2000) also provides a similar definition, seeing subjective well-being as the positive evaluation or affirmative attitude toward real life after comparing real life with expectations about one's life. Since the 1950s, the study of subjective well-being has drawn extensive attention from various academic disciplines such as economics and psychology and sociology. Previous research has mainly discussed factors affecting subjective well-being. Among existing empirical studies, the relationship between employment status and subjective well-being is one of the topics receiving the most attention.

The most commonly used theoretical explanation for the relationship between employment and subjective well-being is the functionalist view proposed by Jahoda (1982). According to this view, in modern industrial society, employment is an important institutional setting in which individuals achieve their basic psychological needs. This is because it provides five latent functions: (1) a time structure, (2) social contacts, (3) participating in collective goals, (4) status and identity, and (5) regular activity. When one is unemployed or out of work, these needs cannot be met and this will result in individuals having a sense of deprivation and, consequently, will negatively affect their subjective well-being (Jahoda 1982).

Jahoda's theory was once widely accepted. However, the theory has a strong orientation of structural functionalism, which assumes all individuals are passive in accepting external structural conditions. In other words, it assumes that influences from structural factors affect all individuals identically. Jahoda's theory was criticized for its functionalist assumption. For example, Fryer (1986) contends that individuals are intrinsically motivated agents and that different individuals are differentially affected by unemployment. Besides, according to some empirical findings, the characteristics of jobs or occupations are also important in shaping the relationship between employment and happiness. For example, some studies show that temporary workers, non-contract workers, and part-time workers are less satisfied or less happy than full-time or contract laborers; others find that there are differences to a certain degree in subjective well-being between self-employed people and employed workers (Dolan et al. 2008). In short, the relationship between employment and subjective well-being might be affected by individual characteristics, job features, and the macro-structural environment. 
Work hours, work-family conflict, and subjective well-being

In addition to overall employment status (employed or not) and job characteristics, the number of hours worked is also an important indicator of employment status. There are two major reasons why total work hours must be considered in estimating the factors affecting subjective well-being. Firstly, there is a direct association between total work hours and the subjective well-being of individuals. According to the existing literature, overwork may have a serious negative effect on physical and mental health, job satisfaction, and even the family relationship of employed workers (Jacobs and Gerson 2004; Golden and Barbara 2006).

Secondly, total work hours is also closely related to work-family conflict, which is a key factor affecting the subjective well-being of individuals, especially women. Workfamily conflict refers to the conflict in roles that occurs when an employed person cannot simultaneously fulfill their duties at work and at home (Greenhaus and Beutell 1985). In modern societies, work-family conflict has been becoming a very common social phenomenon, one leading to serious consequences for individuals, families, and work organizations (Jacobs and Gerson 2004; Nomaguchi 2009). Some researchers consider time conflict (the distribution of time spent for work and family) as a basic form of work-family conflict. When more time is spent in the labor market, it may inevitably squeeze the time that can be spent at home (Greenhaus and Beutell 1985).

In China, the work-family conflict caused by longer total work hours has recently begun to receive attention from Chinese sociologists. Analyzing data collected from five provincial cities in China, Zhang and colleagues (Zhang et al. 2008) found that, other things being equal, employed women spend $20+$ hours more than employed men on housework every week. Another study also discovered that, even if women and men spent the same number of hours working, employed women in urban China spend significantly more hours on housework than men (Tong and Zhou 2013).

With the rapid development of the Chinese economy, the pursuit of happiness has become increasingly important to Chinese people. The Chinese government has been devoting more resources to improving citizen's subjective well-being. At the same time, research on happiness has been flourishing in China and a number of books and research articles have been published (e.g., Bian and Xiao 2014; Bian et al. 2015; Easterlin et al. 2012; Liu et al. 2012). However, few studies have examined the relationship between employment status and subjective well-being at the individual level. In most existing empirical studies, employment status is usually regarded as a control variable. In the current study, we aim to explore the role that employment status plays in shaping women's sense of happiness. Following the market reform that started in the late 1970s, more and more women in urban China have withdrawn from paid work due to changes in labor policies, the rapid transformation of the Chinese labor market, and shifting attitudes about gender roles. In this context, the study of women's employment status and their subjective well-being may shed light on how the great social transformation triggered by market reform has shaped women's life opportunities and their subjective experience.

\section{Theoretical perspective and research hypothesis}

As mentioned in the last section, to account for the relationship between employment status and each individual's subjective well-being, most previous studies have focused 
on the latent functions of employment, various job characteristics, and work-family conflicts caused by long work hours. We argue that the existing literature fails to fully consider the structure of the labor market and the macro-institutional environment of today's urban China, which are of great importance in furthering our understanding of women's employment status and their subjective well-being. In this study, we employ the theory of new institutionalism as it pertains to sociology to frame our empirical analyses. The key notion of new institutionalism, as it pertains to sociology, highlights the importance of the institutional environment in defining individuals' self-conception and identity and in guiding individuals' behaviors. Compared to traditional institutionalism, new institutionalism maintains that the institution has multiple dimensions, not only including its formal characteristics (e.g., regulations or rules in formal organizations) but also including informal characteristics (which mainly refers to the framework of meanings, such as social values, cultural traditions, and norms). According to Richard Scott (Scott 2010: 56), an institution can be defined by the regulative, normative, and cultural cognitive factors that provide consistent meaning for social life as well as for related activities and resources. Based on this theoretical perspective, actions, subjective perceptions, and value judgments by individuals are embedded in formal and informal institutions, and as a result, individual activities and preferences can be understood within a specific institutional environment. In the current study, we argue that women's labor force activities and perception of happiness are closely related to both the formal institutional environment (e.g., structure and regulations of the urban labor market in China) and informal institutional environment (e.g., gender role attitudes and the pattern of gender division of labor in society). Beginning with the reform and opening up policy that began in the late 1970s, the institutional environment in urban China has been experiencing great transformation. On the one hand, the market transition has its impact on gender inequality in the labor market, as well as gender role attitudes. On the other hand, formal institutions in the urban labor market have also been shifting from a redistributive regime to socialism with Chinese characteristics (coexistence of the state and market). As a result, the labor market in urban China is segmented, with the public (state) sector and the private (market) sector coexisting during this market transition.

\section{Market transition, gender inequality in the labor market, and shifting attitudes toward gender roles}

During the redistributive era between 1949 and 1978, due to the egalitarian ideology and regulations about gender equality, Chinese women participated intensively in paid work and, consequently, the gender pay gap was minimized. Since the market reform of 1978, the situation has changed greatly. The socialist ideology of gender equality has faded, and the state patronage of women has been weakening as the power of work units has declined. Meanwhile, due to the mechanism of market competition and gender discrimination, women in the labor market have increasingly begun to face disadvantage in the labor market. Firstly, the gender gap in wages has been steadily widening in the urban labor market, according to quite a few empirical studies (Wang et al. 2008; Li et al. 2014). Secondly, sex discrimination and gender disparities have also emerged as women seek jobs and aim for career promotions (Tong and Liang 2006; Qin 2014). Thirdly, in urban China, a new trend has emerged in which more and more female laborers enter into 
atypical jobs or secondary labor markets where they receive low pay, insufficient benefits, and low job security (Tan and Li 2003; Jin 2006).

At the same time, gender role attitudes in China have been shifting. The socialist ideology reflected in saying like "women hold up half the sky," an idea that was widely accepted during the pre-reform era, has been challenged. The notion that "men are breadwinners while women are housekeepers" has become a more commonly accepted view. Social media and scholars have heatedly debated whether or not women should exit from the labor market (Jiang 2001). Traditional gender-based sayings like "a good marriage is superior to a good career for women" have regained their popularity (Wu 2010). Findings from empirical studies confirm that, since the market reform, traditional gender role attitudes have been revived in China. For example, analyzing data from "Survey of Chinese Women's Social Status" conducted in 1990, 2000, and 2010, researchers found that, in 1990, $44.2 \%$ of people agreed with the idea that "men are breadwinners while women are housekeepers," and this number increased to $47.5 \%$ in 2000 and $57.8 \%$ in 2010. In 2000, 34\% of Chinese people agreed with the saying that "a good marriage is superior to a good career for women," and by 2010, this number rose to $44 \%$ (Feng and Xiao 2014).

In sum, since the market reform, the institutional environment of the labor market in urban China has been changing shape. As confirmed by empirical studies, the gender pay gap and gender discrimination in hiring has been increasing. We also detect a resurgence of traditional gender norms. Under such a gendered institutional environment, we expect that some women make take "returning home" as a "rational" choice since it could help them to escape from the unfriendly (for women) labor market. In recent years, "being housewives" has been becoming a non-negligible social phenomenon in urban China, that is, more and more women, including some highly educated women, have been opting out from paid work (Wu 2014).

\section{Market transition and segmented labor market in Urban China}

An important feature of Chinese market reform is its gradual strategy (compared to the radical reform seen in other transitional nations) and co-existence of state and market. During the market transition, the share of private sector jobs in the urban labor market has been growing, while state sector jobs (e.g., those in state-owned enterprises) continue to be an important part of the economy. Such path toward reform leads to a segmented labor market in urban China, with jobs in the public (state) sector and jobs in the private (market) sector. The two sectors have a sharp boundary between them and differ greatly in the hiring process, payment, or reward system, as well as social welfare and security (Cai 1998). On the one hand, empirical studies reveal that the average wage level and even the rate of wage growth are both higher in the state sector than in the private sector (Xia et al. 2012). On the other hand, firms and companies in the state sector, as was true for the "work units" in the redistributive era before market reform, provide quality social welfare benefits (pension, health care, and child-care, etc.) for their employees (Li 2013). However, the benefit system in the private sector is not comparable to that in the state sector, although it has been improving each year. In a word, the labor market of the public sector shows the basic characteristics of a primary labor market following the theory of labor market segmentation (Piore 2001), namely higher salary, better benefits, job stability, and higher social prestige. 
There are also sector differences in gender inequality. Firstly, although the overall income gap between men and women shows a trend of steadily increasing incomes, the gender wage gap in the public sector is narrower than that in the private sector (Wang et al. 2008; Li et al. 2014). Secondly, women working in the public sector benefit more from the social security policy. China's labor security system is still immature during the transitional period, and as a result, it has not yet been effectively implemented in the private sector, which is poorly regulated. In some private firms or companies (small firms or companies in particular), profit-driven employers might even look for ways to cut maternal leave costs for their female employees, making it difficult for these women to secure their full benefits. In short, compared to the private sector, the public sector provides better benefits for women and better protection of women's rights.

Furthermore, sector disparities can also be seen both in the implementation of formal institutions as well as the effectiveness of implementation. One good example of this can be seen in differences in total work hours across different sectors. A previous study found that as China has increasingly become a market economy, this process has hastened the de-institutionalization of standard work hours. This is because standard work hours $^{1}$ are more common among public sector workers but far less common among those private sector workers, especially those working for small employers, which are subject to outside scrutiny to a lesser extent (Cao and Rubin 2014). The implementation of the standard work hour system in China also varies from the public sector to the private sector in an obvious way. Public sector organizations, especially public service departments, have a better chance of being directly supervised by related government agencies; as a result, the implementation of labor laws and relevant policies can be basically guaranteed, and thus, the phenomenon of overtime work is not common. However, in the labor market environment of private companies, which experiences poorly regulation, profit-driven employers tend to extend the work hours to reduce operational cost, and thus, overtime work is very common (Feng and Li 2013; Li et al. 2012). In private firms or companies, overtime work comes from two different sources. In the high-end labor market, white collar workers in large companies are faced with fierce competition for promotion and performance assessment, such that overtime work then becomes more common and even becomes part of the culture or an unwritten norm (Jacobs and Gerson 2004). In small companies or less high-end labor markets, however, people work overtime because they are forced to do so by the employers who want to maximize their profit by increasing employees' work hours. Due to the low salaries paid by some small employers, some workers are willing to work longer hours in order to increase their take-home pay (Li et al. 2012).

\section{Family patronage, institutional patronage, and work-family conflict: hypotheses}

We argue that the informal (shifting gender role attitudes) and formal (public-private divide of the urban labor market) institutional environment in urban China may affect women's labor supply and the association between women's employment status and subjective well-being. To test this view, we propose three theoretical concepts, namely family patronage, institutional patronage, and work-family conflict, to account for women's labor market activities and their sense of happiness in urban China. In the remainder of this section, we elaborate on these three concepts and, accordingly, formulate hypotheses that are subject to empirical testing. 


\section{Family patronage}

Family patronage refers to the mechanism by which the family provides economic resources, psychological satisfaction, and role identity for women to help them escape from labor market risks. As stated above, growing sex discrimination and gender inequality in the labor market may restrict women's willingness to seek and retain employment. Meanwhile, the revival of traditional gender role attitudes, which could be seen as an informal institutional context, has legitimated the role of "being a housewife," and consequently, withdrawing from paid work and returning home may become a reasonable option for women. Since women's labor supply is a function of the family's economic situation, family sponsorship plays a key role in women's labor market decisions. In this empirical analysis, we use marital status and family economic situation (income of other family members) as indicators of the family patronage mechanism. For women, marriage on the one hand means that they can obtain financial support from their husbands when they do not receive income from the labor market and, on the other hand, means that women can have a legitimate identity as "housewife" at home, given their responsibility for additional housework. Family economic situation is a factor that directly affects women in making decisions about work and their subjective well-being. The worse the economic condition of a family, the more it is necessary for a woman to receive income from the job market to supplement family income (Wu 2014; Wu and Zhou 2015). Following this reasoning, we hypothesize that:

Hypothesis 1: family patronage affects women's labor supply. Specifically,

H1a: ceteris paribus, married women are more likely to be out of the labor force than those who are not married (including women that never marry, are separated or divorced, or widowed).

$H 1 b$ : ceteris paribus, women's employment is negatively associated with family economic situation. Women living in families with higher income from other family members are more likely to be out of the labor force.

Family patronage (marriage and family financial condition) may also be directly related to women's subjective well-being. Firstly, previous studies suggest that marriage plays an important role in boosting an individual's subjective well-being, in particular that of women (Stack and Eshleman 1998). Secondly, most of the existing literature confirms that family income level is an important factor that affects women's subjective well-being. We thus hypothesize that:

Hypothesis 2: family patronage is positively correlated with women's subjective well-being.

$H 2 a$ : ceteris paribus, married women are happier than unmarried women.

$H 2 b$ : ceteris paribus, family economic situation is positively related to women's subjective well-being.

According to the functionalist view of employment proposed by Jahoda (1982), employment may meet multiple psychological needs for individuals; therefore, unemployed people may be less happy than employed people because they are deprived of the needs fulfilled by employment. We contend that the relationship between employment and happiness varies according to context. If the family patronage mechanism 
works, that is, if Hypotheses 1 and 2 can be verified, women who are out of paid work are not necessarily less happy (or even happier) than women who are currently employed. Thus,

Hypothesis 3: ceteris paribus, unemployed women are not less happy than employed women.

\section{Institutional patronage}

Institutional patronage refers to resources and security offered to employed women by their employers. As discussed before, the labor market in urban China is segmented (divided into public and private sectors). Jobs in the public sector offer higher salary and better social security, and these may have positive impacts on individual subjective well-being. The extent of gender inequality and discrimination is lower in the public sector than in the private sector. Furthermore, compared to those in the private sector, labor rights, especially standard working time ${ }^{2}$ of employees in the public sector, can also be better guaranteed and protected. Thus, we hypothesize that:

Hypothesis 4: ceteris paribus, average weekly work hours for women who work in the public sector will be fewer than those for women who work in the private sector.

Hypothesis 5: ceteris paribus, the overall level of subjective well-being for women working in the public sector will be higher than that for women working in the private sector.

\section{Work-family conflict}

Shaped simultaneously by formal institutional arrangement and informal institutional environment, work-family conflict plays an important role in the relationship between employment and subjective well-being for women in urban China. On the one hand, employed women have to obey formal organizational rules (institutionalized work hours in this study) in the workplace to meet the employer requirements. On the other hand, due to the traditional pattern of the gendered division of labor, which is now being revived in Chinese society, women are responsible for most of the housework. That is, employed women are likely to experience tension between their careers and their role in the family. The more time they spend at work, the more intense they may experience work-family conflict, which may consequently have a negative impact on work satisfaction or subjective well-being. Findings from previous empirical studies confirm that employed women in Chinese cities experience dual pressures from paid work and household duties (e.g., Tong and Zhou 2013). In the current study, we use total work hours as the indicator of the work-family conflict mechanism and we hypothesize that,

Hypothesis 6: ceteris paribus, women who spend longer hours in the labor market tend to have lower level of subjective well-being.

Furthermore, work-family conflict caused by long work hours may account for the disparity in subjective well-being among women having various employment status types. That is, 
Hypothesis 7: the coefficients of employment status on subjective well-being may become insignificant after controlling for work hours.

\section{Data, variables, and steps in the analyses}

The data employed in the current study are from Chinese General Social Survey of 2013 (CGSS2013), which is a national representative survey. ${ }^{3}$ We use only the urban women sample (including urban women with agricultural Hukou status) because there is not a formal labor market in rural China. That is, most women are self-employed farmers engaging in agricultural production or activities. Since the current study examines the relationship between employment status and subjective well-being, we restrict our sample to women between the ages of 18 to 54 years (55 is the retirement age for employed women in urban China). Moreover, women enrolled in school are also excluded. After these selections, the data set includes 2162 valid cases.

There are three key independent variables in this study, including employment status, total work hours, and subjective well-being. According to detailed information on employment status from the data, we firstly divide all the respondents into employed women and unemployed women. Then, we divide employed women into two categories based on the type and the ownership pattern of the work unit they are working for. Women who work for party agencies and government organizations, state-owned enterprises, state-owned institutions, social organizations, or neighborhood committees are defined as working in the public sector, and the rest are defined as working in the private sector. Therefore, all valid cases are divided into three categories, i. e., women working in the public sector, women working in the private sector, and women who are not in the labor market (unemployed women). The percentages for these three groups are $27.7,42.3$, and $30.0 \%$, respectively.

The amount of total work hours is measured as average weekly total work hours. Also, based on the existing literature, we define overtime work as working over $40 \mathrm{~h}$ every week (standard work hours defined by the law are $8 \mathrm{~h}$ a day, 5 days a week) and define overtime work hours as actual weekly work hours minus 40 (Feng and Li 2013). Subjective well-being is treated as an ordinal variable with "1" indicating very unhappy and " 5 " indicating very happy. The larger the number, the happier the women report being. ${ }^{4}$ Table 1 displays some basic descriptive statistics for all the variables used in the current analysis (by employment status).

Our empirical analysis consists of three parts. Firstly, we estimate factors that influence women's employment status in order to investigate how family patronage affects women's labor force attachment. Secondly, we analyze the differences between total weekly work hours and total overtime work hours between women working in the public sector and those in the private sector. The goal is to examine how the institution protects women's rights and benefits. Thirdly, we investigate the relationship between family factors, employment status, total work hours, and subjective well-being, testing how family patronage, institutional patronage, and work-family conflict shape the subjective well-being of urban women in China.

\section{Results}

Determinants of women's employment status in urban China

The dependent variable for data analyses in this section is women's employment status, which is a categorical variable ( $1=$ working in the public sector, $2=$ working in the 
Table 1 Descriptive statistics of variables (by employment status), CGSS2013

\begin{tabular}{|c|c|c|c|c|}
\hline \multirow[t]{2}{*}{ Variables } & \multicolumn{3}{|c|}{ Employment status } & \multirow{2}{*}{$\begin{array}{l}\text { Difference } \\
\text { test }\end{array}$} \\
\hline & Public sectors & Private sectors & Unemployed & \\
\hline Subjective well-being & & & & $16.80^{*}$ \\
\hline Very unhappy & 0.01 & 0.02 & 0.01 & \\
\hline Relatively unhappy & 0.05 & 0.07 & 0.06 & \\
\hline So-so & 0.17 & 0.23 & 0.19 & \\
\hline Relatively happy & 0.61 & 0.57 & 0.58 & \\
\hline Very happy & 0.15 & 0.11 & 0.16 & \\
\hline Total weekly work hours & 41.66 & 52.59 & - & $186.52^{* * *}$ \\
\hline Total weekly overtime work hours & 4.15 & 13.82 & - & $199.97^{* * *}$ \\
\hline Married & 0.84 & 0.79 & 0.91 & $22.04^{* * *}$ \\
\hline Income of other family members (10,000 RMB) & 5.39 & 4.66 & 5.27 & $2.98^{+}$ \\
\hline Age & 37.88 & 36.78 & 39.89 & $22.35^{* * *}$ \\
\hline Years of schooling & 12.93 & 10.90 & 9.80 & $121.65^{* * *}$ \\
\hline CCP member & 0.17 & 0.05 & 0.03 & $55.59^{* * *}$ \\
\hline Agricultural Hukou status & 0.26 & 0.40 & 0.45 & $26.19^{* * *}$ \\
\hline Self-rated health & 0.78 & 0.78 & 0.70 & $9.14^{* * *}$ \\
\hline Has minor children & 0.71 & 0.78 & 0.59 & $29.52^{* * *}$ \\
\hline Religion & 0.11 & 0.12 & 0.11 & 0.55 \\
\hline Housing area & 4.40 & 4.35 & 4.39 & 1.54 \\
\hline Social welfare & 0.96 & 0.85 & 0.85 & $24.88^{* * *}$ \\
\hline Income (10,000 RMB) & 3.20 & 3.19 & 0.99 & $122.76^{* * *}$ \\
\hline Income of other family members (10,000 RMB) & 5.39 & 4.66 & 5.27 & $2.98^{+}$ \\
\hline Number of cases & 602 & 914 & 646 & \\
\hline
\end{tabular}

Notes: The numbers are means or percentages. The method of difference test is chi-square test, $T$ test, or variance analysis

${ }^{+} p<0.10 ;{ }^{*} p<0.05 ;{ }^{* *} p<0.01 ;{ }^{* * *} p<0.001$

private sector, and $3=$ unemployed). Thus, we employ the multinomial logistic regression model to predict the factors that affect women's employment status. Moreover, since economic development, labor market structure, and social-cultural background differ greatly across cities in China, we use a multi-level (two levels) modeling scheme for our estimation. The unit of the first level is individual (the respondents). The second level is city (prefecture-level cities). That is, individuals are nested in cities. The intercept of individual level model varies from city to city (i.e., random intercept). The model ultimately used is called the two-level mixed effects multinomial logistic regression model (StataCorp LP 2013). The key independent variables are marital status (married $=1$ ) and family economic situation (measured as the total income of other family members), which are operationalizing indicators of family patronage. We control for those commonly used predictors of women's employment described in existing literature, including human capital (measured as years of schooling), age, Hukou status, parental status (whether or not one has children under 18), self-rated health status, and party membership (party member $=1$, otherwise $=0$ ). The coefficients of the determinants of women's employment status are presented in Table 2.

The results in model 1 and model 2 indicate that age and self-rated health affect women's employment status, while Hukou status and parental status have no significant 
Table 2 Two-level mixed effects multinomial logistic regression models that estimate employment status of women in urban China

\begin{tabular}{llll}
\hline Variables & $\begin{array}{l}\text { Model 1 } \\
\text { Public sectors vs } \\
\text { unemployed }\end{array}$ & $\begin{array}{l}\text { Model 2 } \\
\text { Private sectors vs } \\
\text { unemployed }\end{array}$ & $\begin{array}{l}\text { Model 3 } \\
\text { Public sectors vs } \\
\text { private sectors }\end{array}$ \\
\hline $\begin{array}{lll}\text { Age group } \\
26-35\end{array}$ & $0.519^{*}$ & $0.457^{*}$ & 0.150 \\
$36-45$ & $1.066^{* * *}$ & $0.796^{* *}$ & 0.367 \\
$46-54$ & 0.355 & -0.383 & $0.866^{* *}$ \\
Agricultural Hukou status & -0.049 & -0.033 & -0.008 \\
Self-rated health & $0.100^{*}$ & $0.217^{+}$ & -0.115 \\
Has minor children & -0.195 & -0.120 & -0.149 \\
Years of schooling & $0.236^{* * *}$ & $0.060^{* *}$ & $0.195^{* * *}$ \\
CCP member & $1.090^{* * *}$ & 0.252 & $0.826^{* * *}$ \\
Married & $-0.420^{+}$ & $-0.951^{* * *}$ & $0.549^{* *}$ \\
Income of other family members (10,000 RMB) & $-0.041^{* * *}$ & $-0.024^{* *}$ & -0.008 \\
Constant & $-2.876^{* * *}$ & 0.278 & $-3.365^{* * *}$ \\
Random intercept & $0.017^{* *}$ & $0.017^{* *}$ & $0.072^{* * *}$ \\
N & 2162 & 2162 & 2162 \\
Log-likelihood & -2127.07 & -2127.07 & -2108.53 \\
\hline
\end{tabular}

Notes: Due to space limitation, the standard error is not displayed in the table ${ }^{+} p<0.10 ;{ }^{*} p<0.05 ;{ }^{* *} p<0.01 ;{ }^{* * *} p<0.001$

impacts. Human capital (years of schooling) and political capital (party membership) have a significantly positive effect on employment status. Other things being equal, an additional year of education increases the odds of entering the public sector and private sector by $27 \%\left(e^{0.236}-1 \approx 0.266, p<0.001\right)$ and $6 \%\left(e^{0.06}-1 \approx 0.06, p<0.01\right)$, respectively. In short, women with higher education levels are more likely to be employed, and education level has greater predictive power over entering jobs in the public sector than entering jobs in the private sector. Furthermore, women who are party members are more likely to work in the public sector. But compared to unemployed women, party membership does not increase the chance of working in the private sector.

As was expected, marital status affects women's employment status. Being married depresses women's labor force participation, both for the public sector and for the private sector. Moreover, we find the effect of marital status is greater for private sector jobs than for public sector jobs, which indicates that women employed in the private sector are more likely to withdraw from the labor market because of marriage. These results support H1a. Moreover, models 1 and 2 in Table 2 show that the coefficients of other family members' income are significantly negative, meaning that women whose families have greater financial resources are less likely to participate in the labor force. Thus, H1b is supported. In conclusion, the results in Table 2 support Hypothesis 1. Since the market reform that occurred in the late 1970s, employment is no longer mandated by the government but instead is a choice. Based on the traditional pattern of gendered division of labor and gender role attitudes, the phenomenon of women choosing to return home from work is more rational than it had been. However, only women with family patronage (that is, with a spouse or who have greater family resources) can truly choose not to participate in the labor market. 


\section{Sector differences in work hours}

Figure 1a shows that the average weekly work hours for women who have public sector jobs is 41.57 (close to the number of 40, the standard weekly work hours), whereas the number for women who have private sector jobs is 52.30 . The gap between sectors is thus more than $10 \mathrm{~h}$. In addition, there are distinct gender differences in the number of work hours in public sector jobs. Women work five fewer hours than men each week on average $(46.85-41.57=5.28)$. In private sector jobs, the gender gap for total number of work hours is only $1.4 \mathrm{~h}$. This result indicates that the implementation of the standard work hour system varies from the public sector to the private sector. The policy of standard work hours has been implemented more effectively in the public sector than it has been in the private sector. Therefore, concerning work hours, women working in public sector jobs are better protected compared to women working in private sector jobs.

Figure 1b also shows the work hour differences between sectors. As we can see, in the public sector, $68 \%$ of women work no more than $40 \mathrm{~h}$ a week, while in the private sector, this is true for only $31 \%$ of women. Around $22 \%$ of women in the public sector work 1-10 overtime hours per week while in the private sector, $25 \%$ do. Only $8 \%$ of women work 11-20 overtime hours per week in the public sector, but the percentage for the private sector is $20 \%$. The percentage of women who work 21 or more hours of overtime is $2 \%$ in the public sector but $23 \%$ in the private sector. In short, the phenomenon of overtime work is much more common in the private sector than in the public sector, and this validates the institutional patronage mechanism (Hypothesis 4). Women in the private sector work more hours than women in the public sector. There are clear differences in how effectively the rules and laws regarding labor have been implemented in two sectors.

In order to rigorously examine the (overtime) disparity in work hours between the public and private sectors, we adopt a multi-level linear regression model to estimate total weekly work hours and a multi-level tobit regression model to estimate total overtime work hours. ${ }^{5}$ The key independent variable is sector type (public sector or private sector). Control variables include age, years of schooling, party membership, marital status, parenting status, income of other family members, Hukou status, self-rated health, and occupation. The results show that, with other factors being equal, women in the private sector work 8.6 more hours on average per week than those in the public
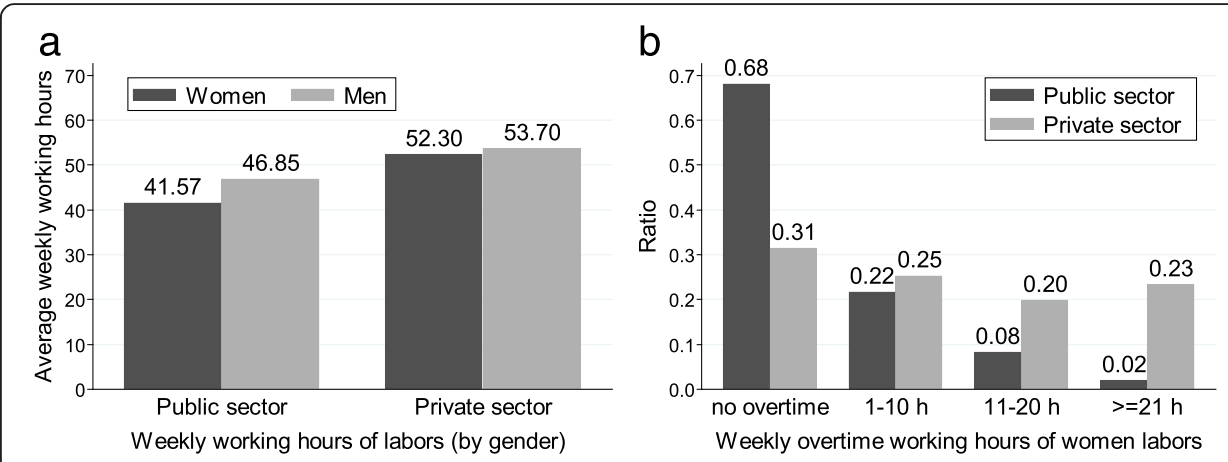

Fig. 1 a, b Sector differences in total work hours and total overtime work hours, 2013 
sector. The gap in weekly overtime work hours is $13.6 .^{6}$ Thus, the results above are consistent with Hypothesis 4 (institutional patronage mechanism).

\section{Employment status, work hours, and subjective well-being}

This section aims to investigate how family patronage, institutional patronage, and work-family conflict influence the subjective well-being of women in urban China. The dependent variable is the respondents' self-reported subjective well-being. The key independent variables are employment status (working in the public sector, working in the private sector, and being out of the labor market), marital status (married =1), family economic situation (income of other family members), and total work hours. Considering the possible nonlinear relationship between total work hours and subjective well-being, we capture work hours as a categorical variable (ordinal scale): 1 refers to women who do not work or women who work but do not work overtime, 2 refers to women who work 41-50 h per week, 3 refers to those who work 51-60 h per week, and 4 refers to those who work over $61 \mathrm{~h}$ per week (category 1 is the reference group in the model). Control variables include age, years of schooling, Hukou status, political identity, religion, parental status, self-rated health, housing status (logarithm of housing area), personal income, social welfare, and self-rated social mobility (upward $=1$, no mobility $=2$, and downward $=3)^{7}$

Since the dependent variable of subjective well-being is an ordinal variable, and considering the economic development and social-cultural background differences across cities in China, a two-level mixed effects ordered logistic regression model (level 1 is individual and level 2 is prefecture level) (StataCorp LP 2013) is adopted for statistical estimation.

Table 3 displays the coefficients of the regression models. Model 1 is the baseline mode, predicting only the effects of the control variables. Model 2 includes two key variables (marital status and income of other family members, which measures family patronage) on the basis of model 1 , in order to test how family patronage influences subjective well-being. Employment status is added in model 3 to examine the differences in subjective well-being for women of various employment status. The variable of total work hours is added in model 4 to estimate how work-family conflict affects subjective well-being and examine the mediation effect of total work hours between employment status and subjective well-being.

We can see from model 1 that education, religion, housing area, social welfare, health, and upward mobility all have positive effects on women's subjective well-being. In contrast, the coefficient of personal income is not significant, meaning that women's own income has little impact on their happiness.

Model 2 shows that, other things being equal, marital status and income of other family members have significantly positive effects on women's subjective well-being $(p<0.001)$. Married women tend to be happier than those who are unmarried. Women with better economic situation (greater income from other family members) are also much happier. This result supports $\mathrm{H} 2 \mathrm{a}$ and $\mathrm{H} 2 \mathrm{~b}$, indicating that family patronage is helpful in increasing women's level of happiness.

Model 3 confirms a significant association between employment status and subjective well-being. The results show that, other things being equal, women employed in public sector jobs and women who are out of the labor force are happier than women who 
Table 3 Multi-level mixed effects ordered logistic regression models to estimate the subjective well-being of women in urban China

\begin{tabular}{|c|c|c|c|c|}
\hline Variable & Model 1 & Model 2 & Model 3 & Model 4 \\
\hline Age & -0.010 & $-0.025^{* * *}$ & $-0.026^{* * *}$ & $-0.026^{* * *}$ \\
\hline Years of schooling & $0.031^{*}$ & 0.025 & 0.021 & 0.014 \\
\hline Agricultural Hukou status & -0.018 & -0.038 & -0.042 & -0.013 \\
\hline CCP member & -0.003 & 0.011 & -0.011 & -0.031 \\
\hline Religion & $0.319^{*}$ & $0.306^{*}$ & $0.314^{*}$ & $0.350^{*}$ \\
\hline Has minor children & -0.083 & -0.204 & -0.166 & -0.174 \\
\hline Housing area & $0.337^{* * *}$ & $0.252^{* *}$ & $0.250^{* *}$ & $0.248^{* *}$ \\
\hline Social welfare & $0.291^{*}$ & $0.276^{*}$ & $0.271^{+}$ & 0.214 \\
\hline Self-rated health & $0.518^{* * *}$ & $0.520^{* * *}$ & $0.529^{* * *}$ & $0.529^{* * *}$ \\
\hline \multicolumn{5}{|l|}{ Subjective social mobility ${ }^{a}$} \\
\hline No mobility & $-0.568^{*}$ & $-0.546^{* * *}$ & $-0.558^{* * *}$ & $-0.563^{* * *}$ \\
\hline Downward mobility & $-1.235^{* * *}$ & $-1.224^{* * *}$ & $-1.261^{* * *}$ & $-1.270^{* * *}$ \\
\hline Personal income (10,000 RMB) & 0.005 & -0.001 & 0.016 & 0.020 \\
\hline Married & & $0.862^{* * *}$ & $0.822^{* * *}$ & $0.849^{* * *}$ \\
\hline Income of other family members $(10,000 \mathrm{RMB})$ & & $0.035^{* * *}$ & $0.031^{* * *}$ & $0.030^{* * *}$ \\
\hline \multicolumn{5}{|l|}{ Employment status $^{\mathrm{b}}$} \\
\hline Work in public sectors & & & $0.267^{*}$ & 0.149 \\
\hline Unemployed & & & $0.440^{* * *}$ & 0.220 \\
\hline \multicolumn{5}{|l|}{ Total weekly work hours ${ }^{c}$} \\
\hline $41-50 \mathrm{~h}$ & & & & $-0.257^{+}$ \\
\hline $51-60 h$ & & & & 0.009 \\
\hline Over $61 \mathrm{~h}$ & & & & $-0.660^{* * *}$ \\
\hline Cutting points & Omitted & Omitted & Omitted & Omitted \\
\hline Random intercept & $0.228^{* * *}$ & $0.213^{* * *}$ & $0.221^{* * *}$ & $0.227^{* * *}$ \\
\hline N & 2162 & 2162 & 2162 & 2162 \\
\hline Log-likelihood & -2359.77 & -2326.69 & -2318.68 & -2309.45 \\
\hline
\end{tabular}

work in private sector jobs. The coefficient is $0.627(p<0.05)$ and $0.440(p<0.001)$, respectively. The level of subjective well-being for women employed in the private sector is the lowest among the three groups. This result on the one hand verifies Hypothesis 5 (women in public sector jobs are happier than women in private sector jobs). On the other hand, it also verifies Hypothesis 3, unemployed women are not less happy than employed women (no matter whether they are employed in the public sector or the private sector). Furthermore, the level of happiness for women out of the labor market is the highest among these three groups according to the results from the coefficients. ${ }^{8}$ If unemployed women receive family patronage and are able to voluntarily withdraw from the labor market, we may conclude that both family patronage and institutional patronage are helpful in boosting women's subjective well-being.

To investigate the effect of total weekly work hours on subjective well-being, we run model 4 by adding three dummy variables that measure total weekly work hours. The 
reference group is work no more than $40 \mathrm{~h}$ a week. The result shows that long work hours indeed has a significantly negative effect on subjective well-being as the coefficient of "work $41-50 \mathrm{~h}$ " is $0.257(p<0.1)$ and the coefficient of "work $61 \mathrm{~h}$ or more" is $0.660(p<0.001){ }^{9}$ This evidence lends support to Hypothesis 6 .

More importantly, model 4 shows that the coefficients of the two dummy variables for employment status decrease sharply and are no longer statistically significant when total work hours is added to the model. This indicates that, after controlling for overtime work hours, the subjective well-being for all the women, no matter their employment status, is basically the same. In other words, the subjective well-being difference between women who work in the public sector, women who work in the private sector, and women out of the labor force can be attributed to a large extent to the difference in work hours. This result verifies Hypothesis 7, which suggests total work hours (especially overtime work hours) is one of the most important mediation mechanisms between employment status and subjective well-being.

We proceed to predict models to construct a pairwise comparison among women of three different employment statuses in order to further investigate whether total work hours is the main cause for the difference in subjective well-being. Table 4 presents the results of multi-level mixed effects ordered logistic models. Model 1a shows, other things being equal, there exists a significant gap in subjective well-being between women in different sectors. However, when the variable of total work hours is controlled for, the coefficient of the employment status decreases from 0.297 to 0.176 and is no longer statistically significant. This suggests that the subjective well-being gap between employed women working in different sectors is mainly caused by the difference in average work hours. Models $2 \mathrm{a}$ and $2 \mathrm{~b}$ compare the subjective well-being gap between women in the public sector and women out of the labor force. There is no significant difference in the subjective well-being between these two groups even when total work hours is included. Model 3a shows that women in the private sector are

Table 4 Multi-level mixed effects ordered logistic regression models to estimate the subjective well-being of women in urban China (pairwise comparison)

\begin{tabular}{|c|c|c|c|c|c|c|}
\hline \multirow[t]{2}{*}{ Variables } & \multicolumn{2}{|c|}{$\begin{array}{l}\text { Public sector vs } \\
\text { private sector }\end{array}$} & \multicolumn{2}{|c|}{$\begin{array}{l}\text { Public sector vs } \\
\text { unemployed }^{\mathrm{b}}\end{array}$} & \multicolumn{2}{|c|}{$\begin{array}{l}\text { Private sector vs } \\
\text { unemployed }^{c}\end{array}$} \\
\hline & Model 1a & Model 1b & Model 2a & Model $2 b$ & Model 3a & Model 3b \\
\hline Employment status & $0.297^{* * *}$ & 0.176 & -0.196 & -0.072 & $0.390^{* *}$ & -0.240 \\
\hline Control variables $^{\#}$ & Controlled & Controlled & Controlled & Controlled & Controlled & Controlled \\
\hline \multicolumn{7}{|c|}{ Total weekly work hours $^{d}$} \\
\hline $41-50 \mathrm{~h}$ & & $-0.342^{*}$ & & $-0.370^{*}$ & & 0.169 \\
\hline $51-60 \mathrm{~h}$ & & -0.123 & & 0.387 & & 0.180 \\
\hline Over $61 \mathrm{~h}$ & & $-0.778^{* * *}$ & & -0.428 & & $-0.588^{* *}$ \\
\hline Cutting points & Omitted & Omitted & Omitted & Omitted & Omitted & Omitted \\
\hline N & 1515 & 1515 & 1515 & 1515 & 1515 & 1515 \\
\hline Log-likelihood & -1646.87 & -1524.12 & -1323.95 & -1321.88 & -1699.95 & -1692.00 \\
\hline
\end{tabular}

${ }^{+} p<0.10 ;{ }^{*} p<0.05 ;{ }^{* *} p<0.01 ;{ }^{* * *} p<0.001$

\#The control variables include age, years of schooling, Hukou status, party membership, religion, marital status, income of other family members, has minor children or not, housing area, social welfare, self-rated health, personal income and self-rated social mobility. Model $1 \mathrm{a}$ and $1 \mathrm{~b}$ also considers occupational type

${ }^{\text {a }}$ Reference group: work in the private sector

${ }^{\mathrm{b}}$ Reference group: unemployed

${ }^{\mathrm{c}}$ Reference group: unemployed

${ }^{\mathrm{d}}$ Reference group: $40 \mathrm{~h}$ or below 
significantly less happy than women out of the labor force (the coefficient is 0.39 , $p<0.001)$. When total work hours is included in model $3 \mathrm{~b}$, the coefficient declines to 0.24 , indicating that to a large extent work hours explains the difference in subjective well-being for those two groups. In conclusion, the findings in Table 4 support Hypothesis 7.

\section{Conclusion and discussion}

Based on the segmented labor market structure of the public sector and the private sector in urban China, this paper divides women into three groups, namely women working in the public sector, women working in the private sector, and women who are out of the labor market. Adopting the theoretical perspective of new institutionalism, we propose three mechanisms, i.e., family patronage, institutional patronage, and workfamily conflict to understand and interpret factors that influence women's employment status and the relationship between employment status and subjective well-being.

We have drawn the following conclusions. Firstly, ceteris paribus, women who are married or have better economic situations are more likely to be out of the labor market. This indicates that though employment is one's independent choice, only those women receiving the patronage of their family can really withdraw from paid work. Secondly, average total work hours per week for women in the private sector is much longer than that for those who work in the public sector. Considering total work hours, women who work in the public sector are provided with more institutional patronage. The third conclusion is that the subjective well-being of women varies from group to group based on employment status. Unemployed women and women working in the public sector tend to be happier than those who work in the private sector. This suggests that both family patronage and institutional patronage can enhance women's sense of happiness. In addition, after controlling for total work hours, there is barely any difference between the subjective well-being of women in the three groups. This indicates that long work hours mediates the effects of employment status on subjective well-being. Long working time not only harms women's physical and mental health but also leads to work-family conflict, which has a negative effect on women's subjective well-being, whether directly or indirectly. The negative influence of work-family conflict is more obvious for women in the private sector because they lack both family patronage and institutional patronage.

The result of this research shows that although employment can provide financial compensation and multiple latent functions meeting the psychological needs of individuals, employment itself does not necessarily uplift one's sense of happiness. When discussing the relationship between employment status and subjective well-being, we should take institutional context or normative environment into consideration. The formal and informal institutional environment of current urban areas of China not only influences women's employment choices but also defines their self-conception and identity as individuals and, consequently, influences their sense of happiness as well.

Based on the empirical findings from the current study, we argue that sufficient attention should be paid to women working in the private sector due to their low levels of subjective well-being (mainly due to their long work hours). Labor laws and relevant rules about standard numbers of work hours are not well regulated in the private sector, and thus, the phenomenon of overtime work is very common, which may have a 
negative influence on the physical and mental health of women as well as on their subjective well-being. Therefore, working in the public sector has become an ideal choice for women. However, getting a job in the public sector is very difficult for low-educated individuals. For women who cannot enter into jobs in the public sector, they might choose to leave the labor market if they have access to family patronage. From the perspective of gender equality, the long-term consequence of women staying out of the labor market cannot be ignored. They will lose their economic independence and occupational network. Most importantly, they might fall into poverty if they divorce or become widows. The ultimate consequence is the further exacerbation of gender inequality. In sum, it is very important to implement strict regulations on the private sector to safeguard workers' rights and formulate policies to encourage female labor force participation and to decrease gender inequality.

The current study has limitations. First of all, the data from CGSS2013 fails to provide information about time spent on housework. This means we are unable to test the direct impact on women's subjective well-being by calculating the sum of total work hours and time spent on housework. Secondly, women within each of the three categories (women who work in the private sector, women who work in public sector, and women who do not work) are also highly differentiated. That is, within-group variations should not be ignored. For example, there are both primary and secondary labor markets in the private sector. There is also differentiation between formal employees and contract workers in the public sector. For women who are out of the labor force, some may have never worked outside the home, while others may choose to become housewives after quitting the labor market. Since the data used in this research did not provide information on correlations, we are unable to elaborate on these differences and their influence on happiness. We will conduct a follow-up study when more detailed information becomes available.

\section{Endnotes}

${ }^{1}$ According to the Chinese Labor Law passed in 1994 and put into effect in 1995, regular daily working time cannot exceed $8 \mathrm{~h}$ and average weekly working time cannot exceed $44 \mathrm{~h}$. Employees are entitled to at least one day off per week as well as several national holidays.

${ }^{2}$ Working time in the current study refers to formal total work hours in the labor market. It does not include time spent on housework.

${ }^{3}$ The data was collected by National Survey Research Center at Renmin University of China. For detailed information, see the center's website http://www.chinagss.org.

${ }^{4}$ Operationalizing subjective well-being into an ordinal level variable is a common and reliable practice in previous literature. See Liu et al. (2012) and Bian and Xiao (2014) for a discussion on the measurement of subjective well-being in China.

${ }^{5} \mathrm{~A}$ large proportion of individuals work 0 overtime hours per week. In statistics, we call this a limited outcome variable. Therefore, the tobit model (with 0 as the lower limit for censoring) is adopted for estimation.

${ }^{6}$ Due to space limits, the outcome of the regression model is not displayed in the text. Contact corresponding author Yuxiao Wu (yxwu2013@nju.edu.cn) for detailed results.

${ }^{7}$ The question in the CGSS2013 survey is "Compared to three years ago, your socioeconomic status is: (1) better; (2) the same; (3) worse; (4) hard to say." We classified "hard to say" as "the same." 
${ }^{8}$ There are no significant differences between the subjective well-being of women working in the public sector and that of women out of the labor force, based on the reestimation results after the reference group was changed.

${ }^{9}$ There exists a nonlinear relationship between total work hours and subjective wellbeing because the coefficient of "work 51-60 h" is not significant in the model.

\section{Acknowledgements}

This study was supported by the "Dengfeng Talents Project (Level B)" research grant from Nanjing University. The authors thank the editor and the anonymous reviewers for their helpful comments and suggestions on the earlier drafts.

\section{Authors' contributions}

YW initiated and designed the study, performed the statistical analysis, and drafted the manuscript. PW participated in the research design and helped to draft the manuscript. $\mathrm{CH}$ participated in the data cleaning, modeling, and making graphs and tables and helped to draft the IV section. All authors read and approved the final manuscript.

\section{Competing interests}

The authors declare that they have no competing interests.

\section{Author details}

${ }^{1}$ Department of Sociology, Nanjing University, Nanjing, China. ${ }^{2}$ Department of Sociology, Shandong University, Jinan, China.

Received: 8 June 2016 Accepted: 8 August 2016

Published online: 02 September 2016

\section{References}

Bian, Yanjie, and Yang Xiao. 2014. A comparative analysis of subjective well-being in China and Britain. Sociological Studies 2: 22-42 [in Chinese].

Bian, Yanjie, Lei Zhang, Jianke Yang, Xiaoxian Guo, and Ming Lei. 2015. Subjective wellbeing of Chinese people: a multifaceted view. Social Indicator Research 121(1): 75-92.

Cai, Fang. 1998. Segmented labor market and changes of employment system transformation in China. Social Sciences in China 2: 4-14 [in Chinese].

Cai, Fang, and Meiyan Wang. 2004. Changing labor force participation in urban China and its implications. Social Sciences in China 4: 68-79 [in Chinese].

Cao, Yang, and B.A. Rubin. 2014. Market transition and the deinstitutionalization of standard work hours in post-socialist China. Industrial and Labor Relations Review 67(3): 864-890.

Diener, E. 2000. Subjective well-being: the science of happiness and a proposal for a national index. American Psychologist 55(1): 34-43.

Dolan, P., T. Peasgood, and M. White. 2008. Do we really know what makes us happy? A review of the economic literature on the factors associated with subjective well-being. Journal of Economic Psychology 29(1): 94-122.

Easterlin, Richard A., Robson Morgan, Malgorzata Switek, and Fei Wang. 2012. China's life satisfaction, 1990-2010. Proceedings of the National Academy of Sciences 109(25): 9775-9780.

Feng, Shizheng, and Ding Li. 2013. Overtime work and social inequality: an empirical research based on CGSS2006 data. Journal of Social Development 2: 170-203.

Feng, Xiaotian, and Jie Xiao. 2014. A research on the differences of female gender role attitude between urban and rural areas. The Journal of Humanities 11: 107-116 [in Chinese].

Fryer, D. 1986. Employment Deprivation and Personal Agency during Unemployment: A Critical Discussion of Jahoda's Explanation of the Psychological Effects of Unemployment. Journal of Neuroendocrinology 25(11): 382-1140.

Golden, L., and W. Barbara. 2006. To your happiness? Extra hours of labor supply and worker well-being. The Journal of Socio-Economics 35(2): 382-397.

Greenhaus, J.H., and N.J. Beutell. 1985. Sources of conflict between work and family roles. Academy of Management Review 10(1): 76-88.

Jacobs, Jarry A., and K. Gerson. 2004. The time divide: work, family, and gender inequality. Cambridge: Harvard University Press.

Jahoda, M. 1982. Employment and unemployment: a socio-psychological analysis. Cambridge: Cambridge University Press.

Jiang, Yongping. 2001. Periodical employment and women returning home around the turn of the century. Collection of Women's Studies 2: 23-28 [in Chinese].

Jin, Yihong. 2006. Female irregular and unstable employment: current situation and countermeasures. Journal of Hohai University 1: 6-10 [in Chinese].

Li, Lulu. 2013. The transition of the work unit system in China. Jilin University Journal Social Sciences Edition 1: 11-14 [in Chinese].

Li, Zhongjin, Yin Chen, Hao Qi, and Xu Zhun. 2012. A living wage, overtime work and China's economic sustainability. China Review of Political Economy 3: 35-57 [in Chinese].

Li, Shi, Jin Song, and Xiaochuan Liu. 2014. The evolution of the gender wage gap of the staff of China's cities and towns. Management World 3: 53-65 [in Chinese].

Liu, Junqiang, Moulin Xiong, and Su Yang. 2012. National sense of happiness in the economic growth period: a study based on CGSS data. Social Sciences in China 12: 82-102 [in Chinese]. 
Nomaguchi, Kei M. 2009. Change in work-family conflict among employed parents between 1977 and 1997. Journal of Marriage and Family 71(1): 15-32.

Pan, Jintang. 2002. Employment and social welfare of Chinese women during market transition. Management World 7: 59-68 [in Chinese].

Parish, W.L., and S. Busse. 2000. Gender and work. In Chinese urban life under reform: the changing social contract, ed. Tang Wenfang and W.L. Parish. New York: Cambridge University Press.

Piore, M.J. 2001. The dual labor market: theory and application. In Social stratification: class, race, and gender in sociological perspective, ed. David B. Grusky. Boulder: Westview Press.

Qin, Guangqiang. 2014. Gender inequality in career advancement: analysis based on CGSS 2006. Sociological Review of China 3: 78-87 [in Chinese].

Scott, W. Richard. 2010. Institution and organization: ideology and material interests (3rd ed.), Translated by Wei Yao and Lifang Wang. Beijing: China Renmin University Press [in Chinese].

Stack, Steven, and J.R. Eshleman. 1998. Marital status and happiness: a 17-nation study. Journal of Marriage and the Family 60(2): 527-536.

StataCorp, L.P. 2013. Stata multilevel mixed-effects reference manual (release 13). College Station: A Stata Press Publication.

Tan, Lin, and Junfeng Li. 2003. A gender analysis on informal employment in China. Population Research 5: 11-18 [in Chinese].

Tong, Xin, and Meng Liang. 2006. Study of gender-based discrimination in employment faced by female university students. Collection of Women's Studies S2: 32-36 [in Chinese].

Tong, Xin, and Lüjun Zhou. 2013. Balancing work and family: comparison based on gender and occupational position. Academia Bimestris 2: $72-77$ [in Chinese].

Veenhoven, Ruut. 1991. Is happiness relative? Social Indicators Research 24(1): 1-34.

Wang, Tianfu, Yang'en Lai, and Bobai Li. 2008. Gender income gap under redistribution and its evolution: 1995-2003. Sociological Studies 2: 23-53 [in Chinese].

Wu, Xiaoying. 2010. Marry well or do well? Women's identity crisis in the market-oriented era and subjectivity construction. In Women's living conditions and social mentality, ed. Xianfan Meng. Beijing: China Social Science Press.

Wu, Xiaoying. 2014. The rise and decline of housewifization: from the perspective of individualization. Social Sciences in Nanjing 2: 62-68 [in Chinese].

Wu, Yuxiao. 2010. Impacts of individual factors on women's employment in urban China: comparison of 1995 and 2002. Chinese Journal of Sociology 6: 136-155 [in Chinese].

Wu, Yuxiao, and Dongyang Zhou. 2015. Women's labor force participation in urban China, 1990-2010. Chinese Sociological Review 47(4): 314-342.

Xia, Qingjie, Shi Li, Lina Song, and Simon Appleton. 2012. Effect of changes in wage structure and employment shares of state-owned units on income distribution: 1988-2007. Economic Research Journal 6: 127-142 [in Chinese].

Zhang, Yuping, E. Hannum, and Meiyan Wang. 2008. Gender-based employment and income differences in urban China: considering the contributions of marriage and parenthood. Social Forces 86(4): 1529-1560.

\section{Submit your manuscript to a SpringerOpen ${ }^{\circ}$ journal and benefit from:}

- Convenient online submission

Rigorous peer review

- Immediate publication on acceptance

- Open access: articles freely available online

- High visibility within the field

Retaining the copyright to your article 